\title{
INCLUSÃO ESCOLAR: EFEITOS DO PLANO NACIONAL DE EDUCAÇÃO NOS PLANOS MUNICIPAIS
}

Neusete Machado Rigo

Morgana Maciel de Oliveira ${ }^{\text {II }}$

I Universidade Federal da Fronteira Sul (UFFS), Cerro Largo (RS), Brasil; neuseterigo@gmail.com

II Universidade Federal da Fronteira Sul (UFFS), Cerro Largo (RS), Brasil; morgana_maciel_oliveira@yahoo.com.br

\section{Resumo}

Este artigo apresenta uma análise sobre as possibilidades de uma política pública nacional desdobrar-se em políticas municipais efetivas. Discute a operacionalização da meta 4 do Plano Nacional de Educação nos planos municipais de educação em relação à formação continuada de professores para a inclusão escolar por abordagem qualitativa, analisando o conteúdo dos planos municipais de educação. Os resultados da pesquisa mostram que os municípios propõem, majoritariamente, formação aos professores do atendimento educacional especializado, em detrimento daqueles que atuam nas salas regulares, concluindo-se que os planos, em geral, distanciam-se da construção de sistemas educacionais inclusivos e seguem uma concepção de educação especial centrada no atendimento educacional especializado.

POĹTICAS EDUCACIONAIS • PLANEJAMENTO EDUCACIONAL • MUNICÍPIOS • FORMAÇÃO CONTINUADA

\section{SCHOOL INCLUSION: EFFECTS OF THE NATIONAL EDUCATION PLAN ON MUNICIPAL PLANS}

\section{Abstract}

This article presents an analysis of the possibilities for public policy, at the national level, to develop into effective municipal policies. Discusses the operationalization of goal 4 of the National Education Plan in the Municipal Education Plans in relation to the continuing education of teachers for school inclusion. The methodology has a qualitative approach and constitutes the content analysis of the Municipal Education Plans. The results of the research indicate that the municipalities mostly propose training directed to teachers of Specialized Educational Assistance, to the detriment of those who work in regular classrooms. Thus, it is concluded that a Plans, in general, distance themselves from the construction of inclusive educational systems, and follow a special education concept centered on the Specialized Educational Assistance.

EDUCATIONAL POLICIES • EDUCATIONAL PLANNING • COUNTIES • CONTINUING EDUCATION 


\section{INCLUSIÓN ESCOLAR: EFECTOS DEL PLAN NACIONAL DE EDUCACIÓN EN LOS PLANES MUNICIPALES}

\section{Resumen}

Este artículo presenta un análisis sobre las posibilidades de una política pública nacional que se desdobla en políticas municipales efectivas. Discute la operacionalización de la meta 4 del Plan Nacional de Educación en los planes municipales de educación en relación a la formación continuada de profesores para la inclusión escolar por aproximación cualitativa, analizando el contenido de los planes municipales de educación. Los resultados de la investigación muestran que los municipios proponen, mayoritariamente, formación a los profesores del atendimiento educacional especializado, en detrimento de aquellos que actúan en las salas regulares, concluyéndose que los planes, en general, se distancian de la construcción de sistemas educacionales inclusivos, y siguen una concepción de educación especial centrada en el atendimiento educacional especializado.

POLÍTICA EDUCATIVA • PLANIFICACIÓN EDUCATIVA • MUNICIPIO • FORMACIÓN CONTINUA

\section{INCLUSION SCOLAIRE : EFFETS DU PLAN NATIONAL D'ÉDUCATION SUR LES PLANS MUNICIPAUX}

\section{Résumé}

Cet article analyse les possibilités d'une politique nationale se déployer en politiques municipales efficaces. Appuyée sur une approche qualitative, la recherche aborde la question de l'opérationnalisation de l'objectif 4 du Plan national de l'éducation dans les plans municipaux de l'éducation concernant la formation continue des enseignants à l'inclusion scolaire et analyse leurs contenus. Les résultats montrent que les municipalités proposent préferentiellement une formation aux enseignants spécialisés au détriment de ceux qui travaillent dans des classes régulières. La conclusion est que les plans sécartent généralement de la construction de systèmes éducatifs inclusifs, au profit d'une conception de l'éducation en milieu spécialisé.

POLITIQUE ÉDUCATIVE • PLANIFICATION ÉDUCATIVE • MUNICIPALITÉ • FORMATION CONTINUE 
INCLUSÃO ESCOLAR TEM PROVOCADO INÚMEROS DEBATES NO CAMPO DA EDUCAÇÃO, desencadeados pela Política Nacional de Educação Especial na Perspectiva da Educação Inclusiva (PNEEPEI), ao propor a inclusão de crianças com deficiências nas escolas regulares, "sem nenhum tipo de discriminação” (2008, p. 5). Passados mais de dez anos do lançamento dessa política, podemos constatar, por meio de pesquisas (Oliveira et al., 2019; Thoma \& Kraemer, 2017; Baptista, 2011, 2015, 2019), o quanto ainda se faz necessário investir em processos formativos de professores visando à inclusão escolar, em relação tanto à formação inicial quanto à formação continuada.

Além da garantia da acessibilidade, a construção de escolas inclusivas depende de mudanças que envolvem princípios éticos, políticos, morais e também concepções pedagógicas e metodológicas para a organização de processos de ensino que garantam a educação de todos. Por isso, são recorrentes pesquisas que problematizam o cenário que conduz a inclusão e as compreensões éticas e pedagógicas presentes nas políticas e nas práticas de inclusão escolar (Baptista, 2015; Carvalho, 2009; Kassar, 2011). Segundo Kassar (2011, p. 10), as análises que fazemos sobre a inclusão escolar devem estar atentas aos apelos feitos pelo contexto político e econômico para uma "convivência com a diversidade e a valorização de conceitos como inclusão, solidariedade, equidade, igualdade", porque, muitas vezes, encobrem "os impactos das políticas econômicas que buscam a implementação de um gerenciamento perfeito dos modos de produção".

Nesse sentido, há que se manter um olhar mais refinado sobre o que fazemos e pensamos sobre a inclusão, a fim de não coadunarmos com propósitos econômicos em que o sistema produtivo aposta quando trata da inclusão (Veiga-Neto \& Lopes, 2007). Não podemos desconsiderar que a inclusão tem sido um mote do neoliberalismo contemporâneo para que todos possam participar dos jogos econômicos, inclusive aqueles que possuem deficiência e que ficam à margem da produtividade. A PNEEPEI (2008) surge nesse contexto e propõe a inclusão das crianças que possuem deficiências, transtornos globais do desenvolvimento e superdotação/altas habilidades nas escolas comuns regulares, e não mais nas escolas e classes especiais. Por isso, as análises que fazemos sobre as propostas de inclusão escolar precisam estar atentas aos interesses de normalização do sujeito com deficiências, que, frequentemente, estão presentes em suas práticas, impedindo que os processos de inclusão produzam outras formas de viver com o outro, reconhecendo singularidades e diferenças.

É salutar destacarmos, no entanto, que a inclusão escolar, durante muitas décadas, foi conduzida, em nosso país, política e pedagogicamente, sob o viés da educação especial segundo uma perspectiva clínica e terapêutica. Além disso, as políticas nacionais de formação de professores, há um curto período de tempo, têm se posicionado a favor de um tipo de formação profissional que inclua a educação especial e a inclusão escolar. Somente a partir de 2001, com as Diretrizes Curriculares Nacionais para a Formação de Professores para a Educação Básica (2001), passa-se a mencionar uma perspectiva de educação inclusiva em normativas relacionadas à formação de professores:

A educação básica deve ser inclusiva, no sentido de atender a uma política de integração dos alunos com necessidades educacionais especiais nas classes comuns dos sistemas de ensino. Isso exige que a formação dos professores das diferentes etapas da educação básica inclua conhecimentos relativos à educação desses alunos. (p. 26)

Nessa direção, em 2015, as Diretrizes Curriculares Nacionais para a formação inicial em nível superior (cursos de licenciatura, cursos de formação pedagógica para graduados e cursos de segunda 
licenciatura) e para a formação continuada (Resolução $n^{\circ} 2$, de $1^{\circ}$ de julho de 2015) reafirmaram a necessidade de formação adequada às modalidades de educação, incluindo a educação especial. Entre os princípios balizadores dessa normativa, está "a formação docente para todas as etapas e modalidades da educação básica como compromisso público de Estado, buscando assegurar o direito das crianças, jovens e adultos à educação de qualidade" (Resolução no 2, de $1^{\circ}$ de julho de 2015, p. 4). Ainda, essas diretrizes definem que os cursos de graduação ou de formação pedagógica para graduados não licenciados ou de segunda licenciatura "deverão garantir nos currículos conteúdos específicos da respectiva área de conhecimento ou interdisciplinares, seus fundamentos e metodologias” (2015, p. 11), incluindo-se aí, também, a modalidade da educação especial.

Embora essas recentes normativas nacionais indiquem a necessidade de a formação de professores abordar conhecimentos da área da educação especial, ainda hoje a maioria dos professores que atuam na educação básica não possui qualquer tipo de formação pedagógica para trabalhar com crianças ou adolescentes que possuam deficiências.

Podemos observar a fragilidade da formação inicial para a inclusão escolar na pesquisa de Mesquita (2007), realizada em uma universidade pública, envolvendo sete cursos de licenciatura. Essa pesquisadora depõe que, embora em um primeiro momento fosse levada a acreditar que a restauração dos projetos pedagógicos dos cursos de licenciatura (após a promulgação das diretrizes nacionais de formação de professores em 2001) se apresentasse coerente à luz de princípios inclusivos, não foi o que encontrou. Os resultados de sua pesquisa indicam que a formação para atuar com o público da educação especial estava "ausente em $28,6 \%$ dos cursos, secundarizada em $42,8 \%$, e presente em apenas 28,6\% do total dos cursos pesquisados" (Mesquita, 2007, p. 181).

Nessa direção, Prais e Rosa (2017), ao apresentarem análises sobre a formação de professores para a inclusão de alunos da educação especial, a partir de pesquisas publicadas em periódico científico no período de 2005 a 2014, alertam que a formação inicial de professores está focada no curso de Pedagogia, em detrimento das demais licenciaturas.

De maneira geral, essas pesquisas mostram que a formação inicial de professores para a inclusão escolar é um desafio às faculdades de educação em todo o país, o que explica a realidade que encontramos nas escolas de educação básica, a qual continua sendo a do "não preparo" dos professores para o ensino com crianças que possuem deficiências.

Consequentemente, isso aumenta a demanda da formação continuada de professores, haja vista que o número de matrículas de crianças com deficiências nas escolas comuns tem crescido significativamente, e às escolas e aos professores não cabe negligenciar o direito à educação. Baptista (2019) discute esse crescimento evidenciado pelos dados do censo escolar de 2016 em relação ao número de matrículas nas escolas comuns, que, em 2003, eram 145.141 alunos e, em 2015, somavam 750.983 no país. Em contrapartida, as matrículas em classes especiais e escolas especiais diminuíram, passando de 358.898 em 2003 para 179.700 em 2015. Segundo esse pesquisador, pode-se reconhecer os efeitos positivos de uma política educacional que manteve o foco na universalização da educação no país, no entanto ele alerta que "é importante que sejam analisadas as condições de escolarização, contemplando dimensões como a participação, os apoios e o desempenho escolar” (Baptista, 2019, p. 11).

Baptista $(2011,2019)$, ao analisar a PNEEPEI, discute também o papel das salas de recursos multifuncionais que foram instaladas a partir de 2007 em todo o país, chegando a atingir $90 \%$ dos municípios brasileiros em 2012 (Baptista, 2019). Essas salas representam um espaço pedagógico para a oferta do Atendimento Educacional Especializado (AEE) aos alunos que são o público da educação especial. Funcionam nas escolas ou em centros de atendimentos e são consideradas espaços prioritários para o desenvolvimento da educação especial por um profissional especializado.

Embora políticas e programas nacionais tenham sido instituídos para a efetivação da inclusão escolar ao longo das últimas décadas, e dados atuais demonstrem que houve um crescimento da 
educação especial nas escolas comuns, os sistemas estaduais e municipais de ensino ainda têm um longo caminho para tornarem-se inclusivos.

Nessa direção, considerando o cenário de fragilidade na formação de professores para trabalhar com crianças e adolescentes que possuem deficiências, realizamos, neste artigo, uma análise do Plano Nacional de Educação de 2014 a 2024 (PNE), em especial da meta 4, que trata da inclusão escolar, e das estratégias definidas nos Planos Municipais de Educação (PME) de uma região do estado do Rio Grande do Sul. Problematizamos a efetivação dessa meta pelos sistemas municipais de ensino no que se refere a:

Universalizar, para a população de 4 (quatro) a 17 (dezessete) anos com deficiência, transtornos globais do desenvolvimento e altas habilidades ou superdotação, o acesso à educação básica ... . preferencialmente na rede regular de ensino, com a garantia de sistema educacional inclusivo ... (Lei n. 13.005, de 2014, itálicos nossos).

Este estudo problematiza um entrelaçamento entre o PNE e a PNEEPEI. Questionamos a "garantia de sistema educacional inclusivo" à educação das crianças que possuem deficiências, transtornos globais do desenvolvimento e superdotação ou altas habilidades, como prevê a meta 4 do PNE. Assim, o que interessa é a análise sobre as possibilidades de uma política pública, em âmbito nacional, desdobrar-se em políticas municipais efetivas. Ou seja, a meta 4 do PNE propõe a universalização da educação às crianças que possuem deficiências em sistemas educacionais inclusivos, mas como os municípios estão estabelecendo suas estratégias para atingi-la nessas condições? Que estratégias estão sendo propostas pelos PME para a efetivação desse propósito? Nosso objetivo neste artigo é refletir sobre as estratégias que os municípios apresentam nos PME para a formação continuada dos professores, visando à construção de sistemas educacionais inclusivos.

\section{Uma política para a construção de uma escola inclusiva}

A proposição da meta 4 do PNE direciona-se à criação de sistemas educacionais inclusivos, o que nos remete à reflexão sobre em quais condições e possibilidades tal realidade poderia ser concretizada. De tal forma, um sistema educacional não pode ficar restrito ao desenvolvimento de ações no espaço escolar e às suas práticas pedagógicas. As estratégias relativas a essa meta indicam ações em nível macro que, por sua vez, induzem ações nos microespaços, que incluem desde a destinação de recursos financeiros, qualificação de espaços pedagógicos, elaboração de programas, garantia de acesso e permanência, articulação entre órgãos públicos, até a formação de professores.

Nesse sentido, o PNE age como uma política pública que constitui um quadro normativo de ações, combinando elementos de força pública e competências que tendem a formar uma força local (Muller \& Surel, 2010). Como política nacional, impulsiona a definição de ações localizadas em âmbitos estadual e municipal e, inclusive, escolar. Isso porque,

para que uma política pública "exista", é preciso que as diferentes declarações e/ou decisões sejam reunidas por um quadro geral de ação que funcione como uma estrutura de sentido, ou seja, que mobilize elementos de valor e de conhecimento, assim como instrumentos de ação particulares, com o fim de realizar objetivos construídos pelas trocas entre os atores públicos e privados. (Muller \& Surel, 2010, p. 18-19, itálicos dos autores).

Segundo Muller e Surel (2010), as medidas propostas por uma política pública não estão, necessariamente, impressas em um único quadro normativo e cognitivo perfeitamente coerente. Para esses pesquisadores, a criação e a efetivação de uma política dependem dos atores que lidam com seus indicativos e seus propósitos e da interpretação que aqueles fazem desses, além de considerar o público que será atingido por essa política. 
Sob essa compreensão de política pública, empreendemos esta pesquisa a fim de investigar como os municípios estão organizando sua política municipal para a construção de sistemas educacionais inclusivos, como prevê a meta 4 do PNE. Partimos do pressuposto de que é fulcral analisar uma política educacional a partir da ação governamental e da intervenção de outros atores na sua determinação.

Assim, quando a normativa maior propõe a criação de sistemas inclusivos, está indicando aos estados e municípios a necessidade de que sejam estabelecidas ações próprias que deem conta da sua realidade local. Essas ações deverão constar nos Planos Estaduais ou Municipais de Educação como norteadoras das ações das secretarias de educação, como órgãos responsáveis pela condução da política educacional junto às escolas e suas propostas pedagógicas. Nessa direção, a construção de sistemas inclusivos está endereçada também aos espaços escolares, demonstrando articulações dos poderes públicos macro e micro.

O espaço escolar é o locus principal dos processos de inclusão, pois é nele que são vivenciadas práticas inclusivas ou não. Propor um sistema educacional inclusivo significa pensar a construção de uma escola inclusiva. Há, porém, que se problematizar a efetivação de uma inclusão totalizante, pois é uma realidade que sabemos, de antemão, que não será alcançada em sua plenitude. Fabris (2011, p. 35) suscita essa discussão ao explicitar que não há um modelo de inclusão para o qual os professores devem ser preparados, pois seria excesso de otimismo ou equívoco compactuar com o entendimento da "inclusão como um ponto de chegada, como um lugar que definimos a priori, e como uma totalidade, em que o objetivo é a inclusão definitiva e total". Sob outra expectativa, poderíamos compreender que há, nos processos de inclusão escolar, uma abertura para uma visão de in/exclusão "como um processo aberto e incompleto" (Fabris, 2011, p. 35), considerando que ninguém está completamente excluído ou incluído em tudo de forma absoluta. Segundo Fabris, todavia, assumir a perspectiva do inacabamento da inclusão nos encaminha a viver o processo de inclusão como "um desafio constante e sistemático, um colocar-se sempre em marcha" (2011, p. 35).

Assim, quando propomos construir uma escola inclusiva, estamos acolhendo todas as formas de diversidade e reconhecendo as diferenças como parte da natureza humana. Carvalho (2009) destaca que a escola inclusiva vai além da presença dos sujeitos na escola. Se desejarmos essa escola, nossas preocupações deverão estar na remoção das barreiras para a aprendizagem e participação, sendo uma escola de qualidade para todos, independentemente das "características orgânicas, psicossociais, culturais, étnicas ou econômicas" (Carvalho, 2009, p. 114) que os sujeitos possam apresentar.

Analisando a PNEEPEI, podemos constatar que ela foi pensada sobre um tripé composto pela: i) destinação de salas de recursos multifuncionais para a oferta do atendimento educacional especializado; ii) duplicidade do cômputo do valor estipulado por aluno pelo Fundo de Manutenção e Desenvolvimento da Educação Básica (Fundeb); e iii) formação de professores. Esses três fatores aparecem nessa política diferenciando-se das anteriores e são determinantes para a transformação dos espaços escolares, porque evidenciam condições concretas para que os sistemas de ensino possam desdobrar a política nacional em suas políticas locais.

Para o primeiro aspecto, estão previstas as salas de recursos multifuncionais, que se constituem como espaços pedagógicos equipados com condições básicas (materiais pedagógicos e equipamentos tecnológicos) para oferecer AEE aos alunos que são público da educação especial (Resolução n. 4, de 2 de outubro de 2009). Esse trabalho deve ser desempenhado por um professor com formação específica na área de educação especial, o que proporciona uma ação pedagógica especializada no ensino desses alunos. O AEE é realizado em turno oposto à sala de aula comum frequentada pelo aluno, e não é substitutivo, mas complementar e suplementar. Segundo a normativa (Resolução n. 4, de 2 de outubro de 2009) que o regulamenta, seu papel é disponibilizar recursos de acessibilidade e estratégias que diminuam as barreiras para a participação e aprendizagem do aluno. Aos professores que atuam no AEE cabe-lhes: "estabelecer articulação com os professores da sala de aula comum visando à disponibilização 
dos serviços, dos recursos pedagógicos e de acessibilidade e das estratégias que promovem a participação dos alunos nas atividades escolares" (Resolução n. 4, de 2 de outubro de 2009, p. 2).

$\mathrm{O}$ duplo cômputo do Fundeb possibilita aos sistemas de ensino qualificar as práticas dos professores com a aquisição de materiais e recursos, ou, ainda, fazer as adequações necessárias para ajustar o ambiente e os processos didáticos aos alunos que possuem deficiências. O aporte financeiro é um elemento crucial para a organização da escola acessível, cabendo destacar que esse é um elemento novo nas políticas de educação especial, introduzido na PNEEPEI, por considerar a duplicidade da matrícula do aluno, ou seja, ele é matriculado na sala de aula comum e na sala de recursos multifuncionais.

O terceiro elemento que sustenta o tripé da PNEEPEI é a formação de professores. Nesse ponto encontramos, talvez, o maior desafio para a construção de sistemas inclusivos, que é oferecer formação continuada para o contingente de profissionais que atuam na educação geral nas salas de aula comuns. Diferentemente dos professores que estão nas salas de recursos, expressamente habilitados em formação para a docência e especialização em educação especial (Resolução n. 4, de 2 de outubro de 2009), para aqueles que estão nas salas comuns a PNEEPEI não evidencia que deverão passar por processos de formação continuada para obterem a qualificação em educação especial.

A PNEEPEI (2008) declara uma compreensão de que a educação especial é aquela que ocorre na sala de AEE, exclusivamente. Apesar de constar em suas diretrizes a "formação de professores para o atendimento educacional especializado e demais profissionais da educação para a inclusão escolar" (p. 14), Bridi (2012, p. 53) nos alerta sobre a "inexistência de referência à formação continuada de professores que atuam nas salas de aula comuns do ensino com alunos da educação especial".

Isso produz um entrave para a inclusão escolar, pois não basta que os sistemas de ensino proporcionem formação continuada para os professores que atuam no AEE, sem investir na formação continuada daqueles que, de fato, desenvolvem o processo de ensino com os alunos que possuem deficiências.

Em decorrência disso, temos um enorme desafio para a construção de escolas inclusivas; porque, sem uma sólida articulação entre a educação especial e a educação geral, dificilmente se efetivarão processos inclusivos. Mesmo que os professores do AEE estabeleçam articulações pedagógicas com aqueles que estão nas salas comuns, ainda assim, a formação continuada destes últimos é primordial para a qualificação das práticas pedagógicas inclusivas.

\section{Caminhos metodológicos}

Este estudo aplica uma metodologia qualitativa por meio da análise documental, seguindo a proposta de Lüdke e André (1986, p. 39) de que os documentos "não são apenas uma fonte de informação contextualizada, mas surgem num determinado contexto e oferecem informaçóes sobre esse contexto". Os documentos analisados são o PNE, instituído pela Lei n. 13.005/2014, composto de vinte metas para a educação nacional, com vigência de dez anos (de 2014 a 2024), e os PME de um conjunto de municípios do estado do Rio Grande do Sul.

O PNE foi aprovado após um longo e amplo debate nacional desencadeado em 2009, que reuniu diversos segmentos da sociedade educacional vinculados a todos os níveis e modalidades de ensino, com representações dos setores público e privado, para definir um plano nacional de educação articulado entre a União, estados e municípios. Não podemos ignorar que a aprovação do plano passou também por acalorados debates no Congresso Nacional e no Senado ao longo de quatro anos até sua aprovação em 2014, representando uma intensa disputa na política educacional brasileira. 
Os PME analisados pertencem aos 25 municípios que integram a região das Missões ${ }^{1}$ disponibilizados no site do Ministério da Educação (MEC) (PNE em Movimento, 2020). Os dados que constituíram o corpus analítico deste estudo foram as estratégias expressas nos PMEs elencadas para o cumprimento da meta 4 do PNE.

Para desenvolver o estudo desses documentos, adotamos a análise de conteúdo, proposta por Lüdke e André (1986), considerando uma categoria definida a priori, direcionada para a formação continuada de professores. Elegemos alguns questionamentos para guiar essa análise: que tipo de formação continuada está sendo proposto no PNE e nos PME? Quais estratégias do PNE e dos PME indicam formação continuada de professores para a educação de crianças com deficiências? Quais os professores envolvidos nessas propostas? Que possibilidades existem para essa formação continuada promover sistemas inclusivos?

O foco das análises no PNE manteve-se nas 19 estratégias da meta 4 do PNE, e, após uma "leitura flutuante", constatamos que estão concentradas nas seguintes questões: a) regulamentos financeiros; b) implantação das salas de recursos e centros de atendimento educacional especializado; c) previsão de programas complementares para a acessibilidade arquitetônica e mobilidade; d) acesso, permanência e atendimento aos alunos com deficiências por equipes profissionais; e) fomento a pesquisas para subsidiar a política de inclusão; f) articulação interinstitucional entre órgãos e políticas públicas; g) avaliação e acompanhamento da política de inclusão; e h) preocupação com a formação dos professores.

Dessa busca, evidenciou-se que, no PNE, existem duas estratégias que tratam da formação continuada de professores, mas nenhuma está direcionada aos professores que atuam nas salas de aula comuns, somente no AEE.

$\mathrm{Na}$ análise dos $25 \mathrm{PME}$, verificamos a direção tomada por suas estratégias em relação à formação continuada para a inclusão escolar. Do total dos planos, encontramos 14 que apontaram formação continuada para professores que atuam no AEE, especificamente, sem mencionar formação aos demais professores; porém, destes, dois planos (PME5, PME8) mencionaram formação para o AEE em uma "perspectiva inclusiva", indicando que a inclusão se dá para além da sala de AEE, ou seja, envolve toda a escola. Entre os demais, 11 planos indicaram a formação continuada para os professores em geral; destes, um (PME1) mencionou formação continuada para gestores, educadores, estudantes e familiares, e um (PME20) apresentou uma visão ampliada da inclusão escolar, expondo várias estratégias desse viés; ainda, um plano (PME18) não fez referência à formação continuada nas estratégias da meta 4, mas previu, no texto geral do PME, a necessidade de operacionalizar os projetos políticos pedagógicos de forma que todos possam aprender juntos, com ou sem deficiências, demonstrando preocupação com a diversidade e com a necessidade de formação continuada aos profissionais da escola.

No quadro a seguir, apresentamos os municípios que fazem parte deste estudo.

QUADRO 1

PLANOS MUNICIPAIS DE EDUCAÇÃO E SEUS RESPECTIVOS MUNICÍPIOS

\begin{tabular}{|c|c|c|c|}
\hline PME$^{2}$ & MUNICÍPIO & PME & MUNICÍPIO \\
\hline PME1 & Bossoroca & PME14 & Roque Gonzales \\
\hline PME2 & Caibaté (não disponível) & PME15 & São Borja \\
\hline PME3 & Cerro Largo & PME16 & Salvador das Missões \\
\hline
\end{tabular}

(Continua)

1 São 26 municípios que integram a região das Missões, Rio Grande do Sul, porém um PME não se encontra disponível para consultas on-line.

2 Para mencionar os planos municipais de educação dos 25 municípios, utilizaremos a expressão PME1, PME2, PME3, e, assim, sucessivamente. 


\begin{tabular}{|c|c|c|c|}
\hline PME & MUNICÍPIO & PME & MUNICÍPIO \\
\hline PME4 & Dezesseis de Novembro & PME17 & Santo Antônio das Missões \\
\hline PME5 & Entre-Ijuís & PME18 & São Luiz Gonzaga \\
\hline PME6 & Eugênio de Castro & PME19 & São Miguel das Missões \\
\hline PME7 & Garruchos & PME20 & São Nicolau \\
\hline PME8 & Giruá & PME21 & São Paulo das Missões \\
\hline PME9 & Guarani das Missões & PME22 & São Pedro do Butiá \\
\hline PME10 & Mato Queimado & PME23 & Sete de Setembro \\
\hline PME11 & Pirapó & PME24 & Ubiretama \\
\hline PME12 & Porto Xavier & PME26 & Vitória das Missões \\
\hline PME13 & Rolador & & \\
\hline
\end{tabular}

Fonte: Elaborado pelas autoras.

\section{A formação continuada de professores e a inclusão escolar}

No primeiro movimento de análise dos dados desta pesquisa, lançamos um olhar sobre estratégias relacionadas à formação continuada de professores para a inclusão escolar, presentes no PNE, e encontramos somente duas que abordam esse aspecto, conforme mostra o quadro a seguir.

\section{QUADRO 2}

\section{META 4 DO PNE E ESTRATÉGIAS QUE PREVEEM A FORMAÇÃO CONTINUADA}

Meta 4. Universalizar, para a população de quatro a dezessete anos com deficiência, transtornos globais do desenvolvimento e altas habilidades ou superdotação, o acesso à educação básica e ao atendimento educacional especializado, preferencialmente na rede regular de ensino, com a garantia de sistema educacional inclusivo, de salas de recursos multifuncionais, classes, escolas ou serviços especializados, públicos ou conveniados.

4.3) Implantar, ao longo deste PNE, salas de recursos multifuncionais e fomentar a formação continuada de professores e professoras para o atendimento educacional especializado nas escolas urbanas, do campo, indígenas e de comunidades quilombolas.

4.18) Promover parcerias com instituições comunitárias, confessionais ou filantrópicas sem fins lucrativos, conveniadas com o poder público, visando a ampliar a oferta de formação continuada e a produção de material didático acessível, assim como os serviços de acessibilidade necessários ao pleno acesso, participação e aprendizagem dos estudantes com deficiência, transtornos globais do desenvolvimento e altas habilidades ou superdotação matriculados na rede pública de ensino.

Fonte: Lei n. 13.005 (2014) (itálicos nossos).

Constatamos, nesse levantamento, que a estratégia 4.3 especifica a formação continuada para professores que atuam no AEE, e a estratégia 4.18 menciona parcerias para ampliar a formação continuada, mas não determina se está dirigida somente aos professores do AEE ou aos docentes em geral. Verificamos também que a formação continuada, de maneira geral, está presente em outras metas e estratégias do PNE relacionadas a públicos diversos e aos níveis e modalidades da educação, porém não estamos considerando esses dados neste estudo.

Nesse sentido, direcionamos nossa reflexão à meta 4 e suas estratégias, considerando-as insuficientes para instituir sistemas educacionais inclusivos. Michels (2011, p. 229) o corrobora ao apresentar resultados de pesquisas sobre a formação de professores para a inclusão escolar. Essa pesquisadora alerta que a formação continuada centrada no AEE não estabelece articulações com a classe comum, e baseia-se "no debate sobre recursos e técnicas específicas relacionadas à deficiência e observa-se a ausência de discussões referentes a processos escolares". Isso leva a compreender "que a proposta de inclusão em curso no país não pressupõe a apropriação do conhecimento escolar por parte dos alunos com deficiência" (Michels, 2011, p. 229). 
O direcionamento da formação continuada aos profissionais do AEE indica um viés presente nas políticas de educação especial que vigoraram no Brasil, e, inclusive, a própria PNEEPEI (2008) em vigência esbarra nessa visão instrumental e funcional em relação às salas de recursos multifuncionais destinadas à oferta do AEE. De acordo com essa política, a educação especial é:

uma modalidade de ensino que perpassa todos os níveis, etapas e modalidade, realiza o atendimento educacional especializado, disponibiliza os recursos e serviços e orienta quanto a sua utilização no processo de ensino e aprendizagem nas turmas comuns do ensino regular. (p. 16).

A intenção de "disponibilizar recursos e serviços" e "orientar a sua utilização" nas turmas comuns deixa implícita a centralidade da ação da sala na deficiência dos alunos. Assim, a visão que está presente nas normativas em vigência no país sugere que há um lugar demarcado exclusivamente para a educação especial, e isso pode ser um agravante para as escolas conduzirem os processos de inclusão.

A Resolução do Conselho Nacional de Educação n. 4, de 2 de outubro de 2009, intensifica essa lógica do AEE, ao instituir diretrizes para a disponibilização de serviços e recursos.

Art. $2^{\circ}$... complementar ou suplementar a formação do aluno por meio da disponibilização de serviços, recursos de acessibilidade e estratégias que eliminem as barreiras para sua plena participação na sociedade e desenvolvimento de sua aprendizagem. (Resolução $n$. 4, de 2 de outubro de 2009, p. 1).

Com isso, não queremos afirmar que essas ações não são necessárias, mas evitar que se estabeleçam disjunções exacerbadas na condução do trabalho pedagógico com o aluno que tenha deficiência e na atuação dos professores - da sala de aula comum e da sala de AEE -, dicotomizando a educação especial e a educação geral.

A relevância assumida pelas estratégias focadas na formação de professores que atuam no AEE, em detrimento à formação em geral dos docentes, afasta-se da construção de políticas de formação continuada para se concentrar no "atendimento" aos alunos. Embora mencione o aspecto "educacional” - atendimento educacional especializado -, este não está isento da perspectiva clínica/ médica/biológica, pela ênfase no termo "atendimento" e "especializado".

Garcia (2013) alerta que o Decreto n. 6.571, de 17 de setembro de 2008, ao discorrer sobre o AEE, já não mencionava o termo educação especial para se referir a um campo de saberes, substituindo-o, portanto, pelo termo "atendimento educacional especializado". Dessa forma, remetia à educação especial "para um modelo centrado nos recursos e a ser desempenhado por um professor com formação específica" (Garcia, 2013, p. 106). Na mesma direção, o Decreto n. 7.611, de 17 de novembro de 2011 definiu orientações à educação especial e ao AEE, influenciando a meta 4 do PNE para dar continuidade a essa perspectiva centrada no AEE, conforme podemos observar nas seguintes estratégias do plano constantes do Quadro 3.

\title{
QUADRO 3
}

\section{A CENTRALIDADE DO AEE NA META 4 DO PNE}

\begin{abstract}
4.3) implantar, ao longo deste PNE, salas de recursos multifuncionais e fomentar a formação continuada de professores e professoras para o atendimento educacional especializado nas escolas urbanas, do campo, indígenas e de comunidades quilombolas;
\end{abstract}

4.4) garantir atendimento educacional especializado em salas de recursos multifuncionais, classes, escolas ou serviços especializados, públicos ou conveniados, nas formas complementar e suplementar, a todos (as) alunos (as) com deficiência [...].

Fonte: Lei n. 13.005 (2014) (itálicos nossos).

Certamente, o apoio pedagógico proporcionado pelo AEE desempenha importante função no processo de inclusão escolar. É necessário, no entanto, que esteja articulado ao ensino da sala de aula comum; caso contrário, manteremos a perspectiva da educação especial como "atendimento 
especializado"; ou seja, de um lado, o AEE e, de outro, a sala de aula comum, que se mantém na normalidade padronizada para trabalhar com alunos considerados "normais", com algumas adaptações àqueles ditos "anormais".

Também encontramos estratégias no PNE que abrem essa perspectiva funcional e indicam a educação inclusiva como um processo geral, que envolve todos os espaços escolares e diferentes profissionais na tarefa educativa. Isso pode ser observado em três estratégias da meta 4 do PNE (Quadro 4).

\section{QUADRO 4}

\section{DIMENSÕES RELACIONAIS DA EDUCAÇÃO INCLUSIVA}

4.8) garantir a oferta de educação inclusiva, vedada a exclusão do ensino regular sob alegação de deficiência e promovida a articulação pedagógica entre o ensino regular e o atendimento educacional especializado;

4.16) incentivar a inclusão nos cursos de licenciatura e nos demais cursos de formação para profissionais da educação, inclusive em nível de pós-graduação, observado o disposto no caput do art. 207 da Constituição Federal, dos referenciais teóricos, das teorias de aprendizagem e dos processos de ensino-aprendizagem relacionados ao atendimento educacional de alunos com deficiência, transtornos globais do desenvolvimento e altas habilidades ou superdotação;

4.19) promover parcerias com instituições comunitárias, confessionais ou filantrópicas sem fins lucrativos, conveniadas com o poder público, a fim de favorecer a participação das famílias e da sociedade na construção do sistema educacional inclusivo.

Fonte: Lei n. 13.005 (2014) (itálicos nossos).

A estratégia 4.8 indica a "promoção da articulação pedagógica" entre as salas (comum e especializada), mas está focada no ensino e no atendimento. Já a estratégia 4.16 propõe-se a "incentivar" a inclusão de referenciais teóricos relacionados à inclusão escolar nos cursos de licenciatura. Ora, com a crescente demanda de educação pelo público da educação especial, não se pode aceitar que esse tipo de formação seja uma simples opção dos cursos em incluir ou não referenciais teóricos que abordem os processos de ensino e aprendizagem desses alunos. A inserção de referenciais éticos, filosóficos, políticos e pedagógicos que discutam a inclusão é imprescindível para redimensionar o papel da escola numa sociedade marcada por exclusões e preconceitos de diferentes ordens, como é a nossa. Além disso, é preciso “investir em propostas teórico-metodológicas que promovam a relação escola-universidade no intuito de contribuir para a formação desses profissionais, por meio de atividades mediadas por processos colaborativos que os considerem dentro de uma perspectiva crítico-reflexiva" (Victor, 2011, p. 92).

No segundo movimento de nossas análises, identificamos nos PME estratégias que fomentam a formação continuada tanto dos professores que atuam em AEE quanto dos que estão nas salas comuns, as quais apresentamos nos quadros 5 e 6 , a seguir.

QUADRO 5

FORMAÇÃO CONTINUADA PARA PROFESSORES DO AEE

\begin{tabular}{|c|l|}
\hline PME & \multicolumn{1}{c|}{ ESTRATÉGIA } \\
\hline PME5 & $\begin{array}{l}\text { 4.7) Fomentar em colaboração com o Estado, ao longo deste PME, formação continuada de professores para o } \\
\text { atendimento educacional especializado nas escolas urbanas e do campo. (p. 114) }\end{array}$ \\
\hline PME8 & 4.4) Fomentar a formação de professores para o AEE na perspectiva da educação inclusiva. (p. 71) \\
\hline PME9 & $\begin{array}{l}\text { 4.2) Implantar, ao longo deste PME, salas de recursos multifuncionais e fomentar a formação continuada de } \\
\text { professores para o atendimento educacional especializado nas escolas do município. (p. 41) }\end{array}$ \\
\hline PME10 & $\begin{array}{l}\text { 4.2) implantar conforme necessidade, manter e modernizar, ao longo deste PME, salas de recursos multifuncionais } \\
\text { e fomentar a formação continuada de professores para o atendimento educacional especializado nas escolas do } \\
\text { município. (p. 36) }\end{array}$ \\
\hline PME24 & $\begin{array}{l}\text { 4.2) Manter e ampliar, ao longo deste PME, salas de recursos multifuncionais e fomentar a formação continuada } \\
\text { de professores para o atendimento educacional especializado nas escolas do município. (p. 32) }\end{array}$ \\
\hline
\end{tabular}

Fonte: Elaborado pelas autoras. 
Analisando os dados apresentados no Quadro 5, somos levados a ratificar a crítica de Garcia (2013) de que o modelo de educação especial que se desenha no país, partindo de vários documentos, entre eles o PNE e a própria PNEEPEI, identifica-se com as reformas sociais em curso na América Latina desde os anos 1990, pois estão direcionadas à manutenção da base e dos valores da sociedade capitalista. A introdução de processos de formação continuada centrada nos professores que atuam no AEE revela uma visão fragmentada e tecnicista da educação, seguindo a lógica do trabalho determinado por "tarefas" específicas e especializadas. Prossegue a autora asseverando que, "nessa direção, a perspectiva inclusiva não parece contribuir, de modo geral, para o processo de escolarização de estudantes com deficiência, altas habilidades e transtornos globais do desenvolvimento" (Garcia, 2013, p. 109).

Essa perspectiva de gerenciamento da educação em detrimento do debate do caráter pedagógico necessário para as transformações nos processos de ensino e de aprendizagem pode ser também identificada no papel e nas atribuições do professor do AEE e da própria sala de recursos multifuncionais. A sala de recursos é responsável por disponibilizar "serviços, recursos e estratégias para eliminar barreiras", sendo que, ao professor de educação especial, cabe:

I - identificar, elaborar, produzir e organizar serviços, recursos pedagógicos, de acessibilidade e estratégias considerando as necessidades específicas dos alunos público-alvo da Educação Especial; II - elaborar e executar plano de Atendimento Educacional Especializado, avaliando a funcionalidade e a aplicabilidade dos recursos pedagógicos e de acessibilidade; III - organizar o tipo e o número de atendimentos aos alunos na sala de recursos multifuncionais; IV - acompanhar a funcionalidade e a aplicabilidade dos recursos pedagógicos e de acessibilidade na sala de aula comum do ensino regular, bem como em outros ambientes da escola; V - estabelecer parcerias com as áreas intersetoriais na elaboração de estratégias e na disponibilização de recursos de acessibilidade; VI - orientar professores e famílias sobre os recursos pedagógicos e de acessibilidade utilizados pelo aluno; VII - ensinar e usar a tecnologia assistiva de forma a ampliar habilidades funcionais dos alunos, promovendo autonomia e participação; VIII - estabelecer articulação com os professores da sala de aula comum, visando à disponibilização dos serviços, dos recursos pedagógicos e de acessibilidade e das estratégias que promovem a participação dos alunos nas atividades escolares. (Resolução n. 4, de 2 de outubro de 2009, p. 3).

Essas atribuições colocam o professor do AEE - professor da educação especial - no comando do processo de aprendizagem por meio do gerenciamento de "recursos" necessários para o ensino, transformando-o em um "ser multifuncional" (Garcia, 2013, p. 115). O enaltecimento dessa função no processo de inclusão confirma-se ao observarmos as estratégias da meta 4 do PNE, que praticamente não mencionam a formação continuada dos professores em geral, mas sim a formação do professor do AEE visando ao funcionamento da sala de recursos multifuncionais. Os PME tendem a seguir a lógica do PNE. Com algumas perspectivas diferenciadas, constatamos, na análise dos planos municipais, um percentual significativo (próximo a 40\%) que inclui em suas estratégias a formação continuada dos professores em geral, mantendo concomitantemente a formação continuada para o AEE.

Isso nos leva a defender que, para atingirmos a universalização da escolarização aos sujeitos da educação especial, faz-se necessário que as políticas locais não se limitem ao previsto no PNE. Partindo do pressuposto de que o desdobramento de políticas nacionais em políticas locais passa por um processo democrático em que cada ente ou espaço público as assume com autonomia, podemos considerá-las objetos de discussão e de problematização, a fim de serem reconstruídas pelos sujeitos que as protagonizam nas realidades locais em que serão desenvolvidas. Por isso, há que se destacar os PME que consideraram a sua realidade e explicitaram estratégias contemplando a formação continuada para os professores em geral com a intenção de construir sistemas inclusivos. 
QUADRO 6

FORMAÇÃO CONTINUADA PARA PROFESSORES EM GERAL

\begin{tabular}{|c|l|}
\hline PME & \multicolumn{1}{c|}{ ESTRATÉGIA } \\
\hline PME1 & $\begin{array}{l}\text { 4.3) Tornar mais significativa e humanizada a educação, desenvolvendo processos de formação continuada para } \\
\text { gestores, educadores, estudantes (pessoas com deficiência ou não) e familiares. (p. 52) }\end{array}$ \\
\hline PME7 & $\begin{array}{l}\text { - Assegurar no Projeto Pedagógico das escolas a inclusão de atendimento aos alunos com necessidades } \\
\text { especiais, oferecendo formação em serviço aos professores em exercício. (p. 38) } \\
\text { - Capacitar continuamente todos os professores da rede de ensino para que todos estejam aptos a atender alunos } \\
\text { com necessidades especiais e altas habilidades. (p. 38) }\end{array}$ \\
\hline PME15 & $\begin{array}{l}\text { 4.9) Implementar e expandir ... parcerias com IES . . para manter o trabalho de professores da Educação Básica } \\
\text { com estudantes com deficiências . . . dedicando especial atenção na formação e no preparo dos professores das } \\
\text { classes regulares de ensino . . }\end{array}$ \\
\hline PME20 & $\begin{array}{l}\text { 25.2) Assegurar na formação continuada dos profissionais da educação básica, conteúdos referentes às temáticas } \\
\text { da inclusão de pessoas com deficiências, transtornos globais do desenvolvimento, e altas habilidades ou } \\
\text { superdotação; utilizando, inclusive, os cursos oferecidos pelo PAR, bem como, em outros programas de } \\
\text { Educação a Distância. (p. 98) }\end{array}$ \\
\hline PME26 & $\begin{array}{l}\text { 4.5) Garantir a oferta de formação continuada em serviço para os/as professores/as que possuem estudantes } \\
\text { público-alvo da Educação Especial nas salas de ensino regular, bem como para os/as que atendem nas salas de } \\
\text { AEE. (p. 50) }\end{array}$ \\
\hline
\end{tabular}

Fonte: Elaborado pelas autoras.

Como Muller e Surel (2010, p. 24) explicam, as análises sobre políticas devem levar em consideração que o "sentido de uma ação se modifica na medida de sua implementação, e os atores modificam de modo retrospectivo os seus fins em função dos resultados da própria ação que estão em condições de observar e avaliar". Os municípios têm vivenciado desafios, maiores ou menores, com a inclusão escolar, desde o surgimento da PNEEPEI, dependendo da demanda de alunos com deficiências em sua rede de ensino, e isso poderia, no nosso entendimento, justificar a iniciativa de os municípios definirem em seus PME estratégias para oferecer a formação continuada a todos os professores. $\mathrm{O}$ Quadro 6 evidencia os PME elaborados por equipes gestoras que, compreendendo a complexidade desse processo, incorporam a responsabilidade da gestão em ações concretas.

Nesse sentido, Brizolla (2015, p. 37) assevera em suas pesquisas sobre políticas de inclusão:

O desenvolvimento de políticas paralelas locais, convergentes ou alternativas à política central, é tarefa social imprescindível para o avanço da democracia, numa acepção de que a conquista da condição democrática demanda embates e resistências, incorporação e refutação de políticas, mas jamais a simplificadora postura de "desresponsabilização" de alguns dos agentes da política em relação ao processo a ser construído.

Os municípios que incluíram em seus planos estratégias prevendo formação continuada, em geral, atribuíram um sentido próprio e responsável pela inclusão escolar, e foram além da PNEEPEI e do PNE. Michels (2011, p. 225) salienta que na PNEEPEI "nada consta sobre a necessidade de formação aos professores regentes de classe que possuam alunos considerados deficientes em suas salas de aula”. Seus estudos também vêm demonstrando que a formação continuada está sendo a estratégia mais utilizada para formar os professores do AEE, haja vista que a formação inicial deixa a desejar. A autora revela que tanto a formação continuada para aqueles que atuam no AEE quanto "a formação inicial não têm como foco central a articulação entre o AEE e a classe comum. Há, ainda, uma preponderância nas formações de um modelo que secundariza o pedagógico e privilegia o médico-psicológico" (Michels, 2011, p. 229).

Nessa perspectiva de formação continuada se estabelece um paradoxo, pois, ao mesmo tempo que se quer promover a inclusão das crianças com deficiências, mantêm-se perspectivas formativas de professores que racionalizam a sua atuação, segregando educação especial e educação geral.

Imbernón (2010, p. 47) contribui para nossa reflexão ao afirmar que os processos de formação continuada não podem ficar restritos a uma "atualização científica, didática e psicopedagógica". 
Por isso, não basta uma formação que trate de recursos ou metodologias pedagógicas para ensinar aos alunos que possuem deficiências; mais do que isso, são necessárias mudanças quanto à compreensão da constituição desses sujeitos e, principalmente, quanto aos processos normalizantes que são adotados no ensino em geral.

A concepção de formação continuada que a perspectiva da educação inclusiva deve suscitar na educação especial deveria seguir o indicativo de Imbernón (2010, p. 48) de que ela deve ajudar "os professores a descobrir sua teoria, a organizá-la, a fundamentá-la, a revisá-la e destruí-la ou construíla de novo". Ao mesmo tempo, a formação continuada de professores, em geral, também passa pela abordagem das teorias de aprendizagem e dos conhecimentos específicos da educação especial, pois não há como ignorar o conhecimento acumulado pelo campo teórico da educação especial. Não será possível ao professor da classe comum, que não obteve em sua formação acadêmica conhecimentos sobre a educação especial, somente com conhecimentos da educação geral, normalizadores que são com frequência, trabalhar com crianças ou adolescentes público da educação especial.

Por ser a estratégia considerada mais apropriada, a formação continuada passa a ser fundamental para os sistemas de ensino, por isso deve ser planejada e sustentada em referenciais teóricos que possam redimensionar o trabalho da educação especial, retirando-a da centralidade assumida pelo AEE sobre as propostas pedagógicas das escolas. Não somente a educação especial, todavia, deve ser questionada; também a educação geral, pois não basta adaptar a educação aos alunos que possuem deficiências, mas repensar o modelo educacional que sustenta a escola.

As mudanças necessárias para um sistema inclusivo que respeite as diferenças e não esteja interessado em "normalizar" os sujeitos passam pela adoção de referenciais que questionam a supremacia da normalidade e da homogeneidade, abrindo o pensamento para o acolhimento às diferenças e ao reconhecimento do outro. Acolher as diferenças e reconhecer o outro implica alterar as relações binárias que colocam em oposição a normalidade/anormalidade e o eu/outro. Isso só será possível, porém, mediante a compreensão de uma responsabilidade ética que podemos ter em relação à alteridade. Com isso, queremos afirmar que a inclusão escolar e a construção de sistemas inclusivos vão muito além de estratégias técnicas que um plano possa propor. A inclusão implica mudanças que estão situadas no campo da cultura e da ética, e somente a formação continuada crítico-reflexiva poderá abrir caminhos para que sejam problematizados os fundamentos normalizadores que integram a instituição escolar.

\section{Considerações finais}

Nossas intenções com esta pesquisa visavam a investigar a articulação das estratégias adotadas pelo PNE e seus desdobramentos nos municípios, por meio dos PME, para a efetivação da inclusão escolar. Para isso, este estudo construiu uma análise sobre as ações que os órgãos gestores da educação estão organizando para garantir a inclusão escolar nas escolas comuns.

Há dois aspectos que gostaríamos de destacar em relação aos resultados desta pesquisa. O primeiro trata da universalização do acesso à educação previsto na meta 4, o qual compreendemos que pode ser proporcionado pelo cumprimento legal da obrigatoriedade da matrícula e todas as questões estruturais necessárias, mas a aprendizagem e a interação social, aspectos fundamentais para a inclusão, implicam um complexo processo de formação continuada que deve atingir a todos os professores (inclusive os gestores), demandando mais atenção de nossa parte.

O segundo aspecto indica que os esforços da meta 4 do PNE para a construção de "sistemas educacionais inclusivos" são insuficientes por não incidirem, de forma mais intensa, na formação continuada dos professores. Os PME, em geral, seguiram essa lógica apresentando estratégias direcionadas exclusivamente ao atendimento educacional especial, reafirmando a educação especial como a responsável pelo trabalho educativo com os alunos que são o público da política nacional. Alguns municípios, porém, redimensionaram sua política local, definindo estratégias para a formação geral 
dos professores, demonstrando compreender que o AEE e a educação especial, isolados da educação geral, não produzirão as mudanças necessárias para a construção de sistemas inclusivos. Na ausência de propostas de formação continuada de professores em geral, organizadas e conduzidas pela gestão da educação nos municípios, que problematizem a educação especial e seu viés clínico e terapêutico e a própria educação em geral, não teremos condições para viabilizar a inclusão escolar.

Miranda (2011, p. 138) já mencionava algumas dificuldades nesse processo formativo, alertando que a educação inclusiva requer mudanças nas práticas convencionais, e, para isso, o professor deve ser “inquiridor, pesquisador e reflexivo sobre o seu saber-fazer pedagógico". No entanto, para isso, ele deve estar envolvido em processos formativos coletivos que estejam sustentados teoricamente. Nisso estariam, centralmente, a ação dos gestores da educação e as estratégias dos seus planejamentos municipais.

A problematização que nos orientou na análise das estratégias dos PME, relacionadas à formação continuada de professores para a educação de crianças com deficiências, esteve implícita na crítica de que não basta termos uma meta no PNE sobre a inclusão escolar, estando suas estratégias desfocadas da formação dos professores em geral. A inclusão que se espera atingir deve acontecer em toda a escola, mas, principalmente, no espaço da sala de aula comum, na relação entre os sujeitos professor e aluno - e o conhecimento, resultando em possibilidades de aprendizagem. É pertinente, entretanto, destacarmos mais uma vez que as estratégias da meta 4 do PNE direcionam as políticas locais de inclusão escolar, aglutinando-as, prioritariamente, às questões estruturais e organizacionais, deixando uma lacuna em relação aos aspectos pedagógicos.

Nesse sentido, esperamos que este estudo contribua com os sistemas de ensino, fortalecendo suas reflexões, estratégias e ações para conduzir suas políticas municipais de inclusão escolar, compreendendo que ela não é tarefa do AEE, mas da educação em geral. A inclusão escolar implica mudanças na cultura escolar e no pensamento dos professores, suplantando referenciais e pressupostos homogeneizantes por uma visão de heterogeneidade, sustentando-se em compreensões epistemológicas, éticas e filosóficas em direção à alteridade, ao respeito e ao acolhimento das diferenças.

Dorziat (2011, p. 154) recomenda revisar a relação entre a educação especial e a educação geral para pensar a formação de professores:

superando as discussões simplistas em torno de um enfoque generalista ou especializado. Um não exclui o outro, ao contrário, deve existir uma complementaridade entre eles, sustentada pela lógica da diferença. Isso quer dizer que não basta preparar os professores para lidar com as diferenças biológicas dos alunos, de forma específica, mas buscar desestabilizar a pedagogia tradicional da classificação, que se baseia em um suposto padrão de normalidade.

As (im)possibilidades da inclusão escolar não estão dadas, e tampouco são fáceis de serem construídas. Elas dependem da ação dos sujeitos envolvidos nas políticas de inclusão, tanto daqueles que atuam na gestão e na organização dos processos formativos nas secretarias municipais de educação, quanto dos que estão nas direções de escolas ou atuando em sala de aula.

\section{Referências}

Baptista, C. R. (2011, maio/agosto). Ação pedagógica e educação especial: A sala de recursos como prioridade na oferta de serviços especializados. Revista Brasileira de Educação Especial, 17 (Edição especial), 59-76. http://www.scielo.br/pdf/rbee/vl7nspel/06.pdf

Baptista, C. R. (Org.). (2015). Escolarização e deficiência: Configurações nas políticas de inclusão escolar. Marquezine \& Marquezine; ABBE.

Baptista, C. R. (2019). Política pública, educação especial e escolarização no Brasil. Educação e Pesquisa, 45, Artigo e217423, 5-19. http://www.revistas.usp.br/ep/article/view/163912/157407

Bridi, F. R. de S. (2012). Formação continuada em educação especial: $\mathrm{O}$ atendimento educacional especializado. In M. Rozek, \&L. T. Veigas (Orgs.), Educação inclusiva: Politicas, pesquisae formação (pp. 49-62).EDIPUCRS. 
Brizolla, F. (2015). A implantação de políticas públicas de inclusão escolar no Rio Grande do Sul: Memória e trajetória. In C. R. Baptista (Org.), Escolarização e deficiência: Configuraçôes nas politicas de inclusão escolar (pp. 31-42). Marquezine \& Marquezine; ABBE.

Carvalho, R. E. (2009). Educação inclusiva: Com os pingos nos "is". (6a. ed.). Mediação.

Decreto n. 6.571, de 17 de setembro de 2008. (2008, setembro 18). Dispõe sobre o Atendimento Educacional Especializado, regulamenta o parágrafo único do art. 60 de Lei no 9.394, de 20 de dezembro de 1996, e acrescenta dispositivo ao Decreto $\mathrm{n}^{\circ}$ 253, de 13 de novembro de 2007. Diário Oficial da União, p. 26. http://www.planalto.gov.br/ccivil_03/_Ato2007-2010/2008/Decreto/D6571.htm

Decreto n. 7.611, de 17 de novembro de 2011. (2011, novembro 17). Dispõe sobre a educação especial, o atendimento educacional especializado e dá outras providências. Diário Oficial da União, p. 12. http://www.planalto. gov.br/ccivil_03/_Ato2011-2014/2011/Decreto/D7611.htm

Dorziat, A. (2011). A formação de professores e a educação inclusiva: Desafios contemporâneos. In K. R. M. Caiado, D. M. de Jesus, \& C. R. Baptista (Orgs.), Professores e educação especial: Formação em foco (Vol. 2 , pp. 147-159). Mediação.

Fabris, E. H. (2011, janeiro/abril). In/exclusão no currículo escolar: O que fazemos com os “incluídos"? Educação Unisinos, 15(1), 32-39.

Garcia, R. M. C. (2013, janeiro/março). Política de educação especial na perspectiva da educação inclusiva e a formação docente no Brasil. Revista Brasileira de Educação, 18(52), 101-119. http://www.scielo.br/pdf/ rbedu/v18n52/07.pdf

Imbernón, F. (2010). Formação continuada de professores. Artmed.

Kassar, M. C. M. (Org.). (2011). Diálogos com a diversidade: Sentidos da inclusão. Mercado de Letras.

Lei n. 13.005, de 2014. (2014, junho 26). Aprova o Plano Nacional de Educação - PNE e dá outras providências. Diário Oficial da União. Edição extra, p. 1.

Lüdke, M., \& André, M. E. D. A. (1986). Pesquisa em educação: Abordagens qualitativas. EPU.

Mesquita, A. M. A. (2007). A formação inicial de professores e a educação inclusiva: Analisando as propostas de formação dos cursos de licenciatura da UFPA. [Dissertação de mestrado, Universidade Federal do Pará]. http://ppgedufpa.com.br/bv/arquivos/File/dissertacoes2005/amelia_dissertacaoa.pdf

Michels, M. H. (2011, maio/ago.). O que há de novo na formação de professores para a Educação Especial? Revista Educação Especial, 24(40), 219-232. https://www.redalyc.org/pdf/3131/313127402006.pdf

Miranda, T. G. (2011). Desafios da formação: Dialogando com pesquisas. In K. R. M. Caiado, D. M. de Jesus, \& C. R. Baptista (Orgs.), Professores e educação especial: Formação em foco (Vol. 1, pp. 125-141). Mediação.

Muller, P., \& Surel, Y. (2010). A análise das políticas públicas. (2a. ed.). Educat.

Oliveira, A. A. S. de, Fonseca, K. de A., \& Reis, M. R. dos (Orgs.). (2019). Formação de professores e práticas de educação inclusiva. CRV.

Parecer CNE n. 9, de 8 de maio de 2001. (2002, janeiro 18). Diretrizes Curriculares Nacionais para a Formação de Professores da Educação Básica, em nível superior, curso de licenciatura, de graduação plena. Conselho Nacional de Educação. Ministério da Educação. Diário Oficial da União, Seção 1, p. 31. http://portal. mec.gov.br/cne/arquivos/pdf/009.pdf

PNE em Movimento. (2020). Ministério da Educação. http://pne.mec.gov.br/18-planos-subnacionais-deeducacao/36-elaboracao-e-adequacao-dos-planos-subnacionais-de-educacao

Política Nacional da Educação Especial na Perspectiva da Educação Inclusiva. (2008). Ministério da Educação. http://portal.mec.gov.br/arquivos/pdf/politicaeducespecial.pdf

Prais, J. L. de S., \& Rosa, V. F. da. (2017, janeiro/abril). A formação de professores para a inclusão tratada na Revista Brasileira de Educação: Uma análise. Revista de Educação Especial, 30(57), 129-144. https://periodicos. ufsm.br/educacaoespecial/article/view/19833

Resolução n. 4, de 2 de outubro de 2009. Institui as Diretrizes Operacionais para o Atendimento Educacional Especializado na Educação Básica, modalidade educação especial. Conselho Nacional de Educação. Ministério da Educação. http://portal.mec.gov.br/dmdocuments/rceb004_09.pdf 
Resolução n 2, de $1^{\circ}$ de julho de 2015. Define as Diretrizes Curriculares Nacionais para a formação inicial em nível superior (cursos de licenciatura, cursos de formação pedagógica para graduados e cursos de segunda licenciatura) e para a formação continuada. Conselho Nacional de Educação. Ministério da Educação. http://pronacampo.mec.gov.br/images/pdf/res_cne_cp_02_03072015.pdf

Thoma, A. da S., \& Kraemer, G. A. (2017). A educação de pessoas com deficiências no Brasil: Politicas e práticas de governamento. Appris.

Veiga-Neto, A., \& Lopes, M. C. (2007). Inclusão e governamentalidade. Educação e Sociedade, 28(100), 947-963. http://www.scielo.br/scielo.php?pid=S010173302007000300015\&script=sci_abstract\&tlng=pt

Victor, S. L. (2011). Formação inicial e pesquisa-ação colaborativa na UFFS. In K. R. M. Caiado, D. M. de Jesus, \& C. R. Baptista (Orgs.), Professores e educação especial: Formação em foco (Vol. 1, p. 91-104). Mediação.

\section{Nota sobre autoria}

Para a elaboração deste artigo, a primeira autora organizou os dados e realizou a discussão e análise dos resultados. A segunda autora desenvolveu a coleta de dados e também participou da sua organização, da análise e discussão realizada no artigo.

\section{Disponibilidade de dados}

Os dados subjacentes ao texto da pesquisa estão informados no artigo.

\section{Como citar este artigo}

Rigo, N. M., \& Oliveira, M. M. de. (2021) Inclusão escolar: Efeitos do plano nacional de educação nos planos municipais. Cadernos de Pesquisa, 51, Artigo e07304. https://doi.org/10.1590/198053147304 